\title{
Histology and Immunocytochemical Localization of Glial Fibrillary Acidic Protein in the Inner Ear of Scincella tsinlingensis
}

\author{
Histología y Localización Inmunocitoquímica de la Proteína Ácida \\ Fibrilar Glial en el Oído Interno de Scincella tsinlingensis
}

Chun Yang ${ }^{1}$; Huihui Zhang'; Zhaoting Kou ${ }^{1}$; Yuting Zhang'; Zhimei Gao' \& Bo Liu ${ }^{2}$

YANG, C.; ZHANG, H.; KOU, Z.; ZHANG, Y.; GAO, Z. \& LIU, B. Histology and immunocytochemical localization of glial fibrillary acidic protein in the inner ear of Scincella tsinlingensis. Int. J. Morphol., 39(2):497-505, 2021.

SUMMARY: The microstructure of inner ear in Scincella tsinlingensis was observed by light microscopy and the expression of glial fibrillary acidic protein (GFAP) in membranous labyrinth among the juvenile age group, subadult age group and adult age group were also detected by methods of immunohistochemistry. The inner ear in S. tsinlingensis resembled those in other Scincid lizards in their anatomy and histology. Large and elongate cochlear duct was slightly bowed or arched laterally. There was no hint of limbic modifications and the limbic lip was absent in cochlear recess. The basilar papilla elongated anteroventrally possessed specialized tectorial sallets. GFAP staining was significantly distributed in supporting cells of the sensory epithelia of cochlear duct, while the utricular macula and canal ampullae showed immunopositive for the GFAP antibody, with weaker staining in the saccular macula. The membranous inner ear of three different age groups revealed the similar pattern of GFAP expression, which suggested that the distribution of supporting cells were independent of age in $S$. tsinlingensis

KEY WORDS: Scincella tsinlingensis; Inner ear; Histology; Supporting cells.

\section{INTRODUCTION}

The inner ear contains the cochlea and vestibule (Rinkwitz et al., 2001). The former is responsible for the sense of hearing and depends on the sensory hair cells of basilar papilla of the lagena of nonmammalian amniotes, while the latter is necessary for the sense of balance and gravity, which is realized byusing the ampullae of three semicircular canals and the sensory field of utriculus and sacculus (Pfaff et al., 2019). A considerable amount of literature refers to the morphology, comparative anatomy, functional morphology and evolutionary biology has already been published on the labyrinth of vertebrate inner ear. Lizard is a kind of amniotic membrane radiation with more than 6,687 recognized species. The diverse radiation of lizards is accompanied by the diversification of inner ear structure (Manley, 2002), among which the structure of basilar papilla diversity is most significant (Manley \& Köppl, 2008). Histological structure and auditory function have already been reported in several species of lizards, e.g., Scincidae lizards (Wever, 1970), Gekkonomorph lizards (Wever, 1974; Gehr \& Werner, 2005) and Anolis lizards (Dickson et al., 2017), but the number of species covered has been limited.
The sensory epithelium of inner ear is composed of hair cells and supporting cells. A variety of functions and characteristics of hair cells have been determined, but little is known about the biology of supporting cells (Rio et al., 2002). A good marker for supporting cells in the sensory epithelia is used to clarify the expression pattern of glial fibrillary acidic protein (GFAP), in order to understand the cellular mechanisms in inner ear of the adult and developing mice (Rio et al.). After several months of estradiol treatment in the guinea pig, the GFAP is increased in the inner sulcus, Hensen cells and Claudius cells (supporting cells) of inner ear, suggesting that the estradiol treatment may affect the inner ear ionic homeostasis but provide protection through the activated intermediate filaments (Horner et al., 2009).

The family Scincidae is one of the most globally diverse groups of lizards, including 146 genera, and there are about 1650 species currently recognized worldwide (Neang et al., 2018). As an endemic species in China, the ovoviviparous Scincella tsinlingensis belongs to the Scincidae family. Recent study on smooth skink not only

\footnotetext{
${ }^{1}$ School of Life Sciences, Shanxi Normal University, Linfen, Shanxi Province, P.R. China.

${ }^{2}$ Department of Intensive Care Medicine, Hanzhong Central Hospital, Hanzhong, Shaanxi Province, P.R. China.
} 
includes phylogenetics, histomorphology of excretory system and digestive system (Yang \& Wang, 2016), microstructures and ultrastructures of vomeronasal organ (Yang et al., 2020a), but also involves the cytoarchitecture and adult neurogenesis in telencephalon (Yang et al., 2017, 2020b).The effect of $\alpha$-asarone on cell proliferation during the stage of blastema formation in tail regeneration has been researched by immunohistochemistry (Zhao et al., 2020).The expression of GFAP in retina of $S$. tsinlingensis is related to age, which may be involved in the regulation of physiological functions during the development of retina (Gao et al., 2018). However, there are no detailed descriptions of microstructure of inner ear in S. tsinlingensis. It is unclear whether the GFAP positive cell distribution shows age-related changes in the inner ear of $S$. tsinlingensis. Given these concerns, histological serial and thin sections were used to investigate the anatomy of lizard inner ear. Additionally, the GFAP distribution characteristics in the inner ear of lizard were detected by methods of immunohistochemistry among three agegroups.

\section{MATERIAL AND METHOD}

The experimental S. tsinlingensis consisted of 22 individuals from the hilly areas of Qiliyu forest in Taiyue Mountain, Shanxi, China $\left(110^{\circ} 40^{\prime}-112^{\circ} 21^{\prime} \mathrm{E}, 36^{\circ} 21^{\prime}-\right.$ $\left.36^{\circ} 45^{\prime} \mathrm{N}\right)$. Based on the snout-vent length (SVL), these lizards were divided in to the juvenile age group $(\mathrm{n}=4, \mathrm{SVL}<48.08 \mathrm{~mm})$, subadult age group $(\mathrm{n}=4,48.08$ $\mathrm{mm} \leq \mathrm{SVL} \leq 57.08 \mathrm{~mm})$ and adult age group $(\mathrm{n}=10, \mathrm{SVL}>57.08 \mathrm{~mm})$. Experiments were carried out according to protocols approved by animal care guidelines of the Ethical Committee of Shanxi Normal University. The animals were severed with heads after deeply anesthetizing by ether.

Light microscopy. Six head samples from adult lizards were trimmed to a block containing both ears, fixed for 3 days with $4 \%$ paraformaldehyde for light microscopy, and decalcified by Leica surgipath decalcifier I for 1-3 days. Then, samples were dehydrated with graded alcohols, cleared in xylenes, embedded in paraffin wax, serially sectioned from rostral to caudal and stained by hematoxylin-eosin (H-E). Finally, the sections observation and images collection were obtained with Olympus BX51 digital imaging system (Olympus, Tokyo).

Immunohistochemical staining. Twelve head samples from three groups were trimmed to a block containing both ears, fixed and decalcified as the protocols above, which were dehydrated in $15 \%$ and $30 \%$ sucrose solution and then embedded in OCT embedding medium. Horizontal slices of samples were cut at $25 \mu \mathrm{m}$ in freezing microtome (CM-1850, Leica, Germany) and stored at a temperature of $-20^{\circ} \mathrm{C}$. Before immunocytochemistry staining, sections were post-fixed in $4 \%$ paraformaldehyde for $30 \mathrm{~min}$, and then washed in PBS buffer (0.1M, PH 7.4) for 3 times. The primary antibodies employed were rabbit anti-GFAP polyclonal (1:200, including $0.2 \%$ TritonX-100, Boster), incubated at $4{ }^{\circ} \mathrm{C}$ for overnight, washed $3 \times 10 \mathrm{~min}$ in PBS and then incubated in biotinylated goat anti-rabbit $\operatorname{IgG}$ (1:100, Boster) for $2 \mathrm{~h}$ at room temperature. Subsequently, the slides were washed again and incubated with streptavidin-labeled peroxidase complex for $3 \mathrm{~h}$ at room temperature. After further washing with PBS, the diaminobenzidine tetrahydrochloride (DAB) was developed to show the yellow color, and the Olympus BX51 digital imaging system was used to capture images.

\section{RESULTS}

Light microscopy of inner ear in S. tsinlingensis. Similar to other Scincid lizards, the anatomic structure of the inner ear in S. tsinlingensis was composed of lymphatic fluid-filled bone labyrinth and membrane labyrinth. The bone labyrinth consisted of cochlear, vestibule and bone semicircular ducts. The membranous structures of inner ear were enclosed in a bony, or partly otic capsule and cartilaginous, including the semicircular ducts and their ampullae, utricle, saccule and cochlear duct.

The bone labyrinth. The vestibule was a bony capsule with bulbous. The anterior recesses of vestibule contained the anterior and lateral ampullae, as well as the anterior portion of utricle (Figs. 1-A, B, C and D). The posterior recess of vestibule was located in the ampulla of posterior semicircular duct. Behind the middle of vestibule, the anterior and posterior canals were confluent with the main vestibular cavity through the foramen for superior sinus of utricle. The cochlear recess was large, which extended far rostrally and ventrally in $S$. tsinlingensis, located inside the vestibule and connected with vestibule through a large hiatus toward the posterior part of otic capsule (Figs. 1-F, G and D).

The membranous labyrinth. The membranous labyrinth consisted of a series of fluid-filled, epithelium-lined sacs suspended in the vestibule and cochlear cavity (Figs. 1-F, G and $\mathrm{H})$. Located in the middle third of the long vestibular axis, the saccule covered a low cuboidal or columnar epithelium and supported upon the connective tissue (Figs. 2-A and B). Part of the periotic system was formed by organized and den- 


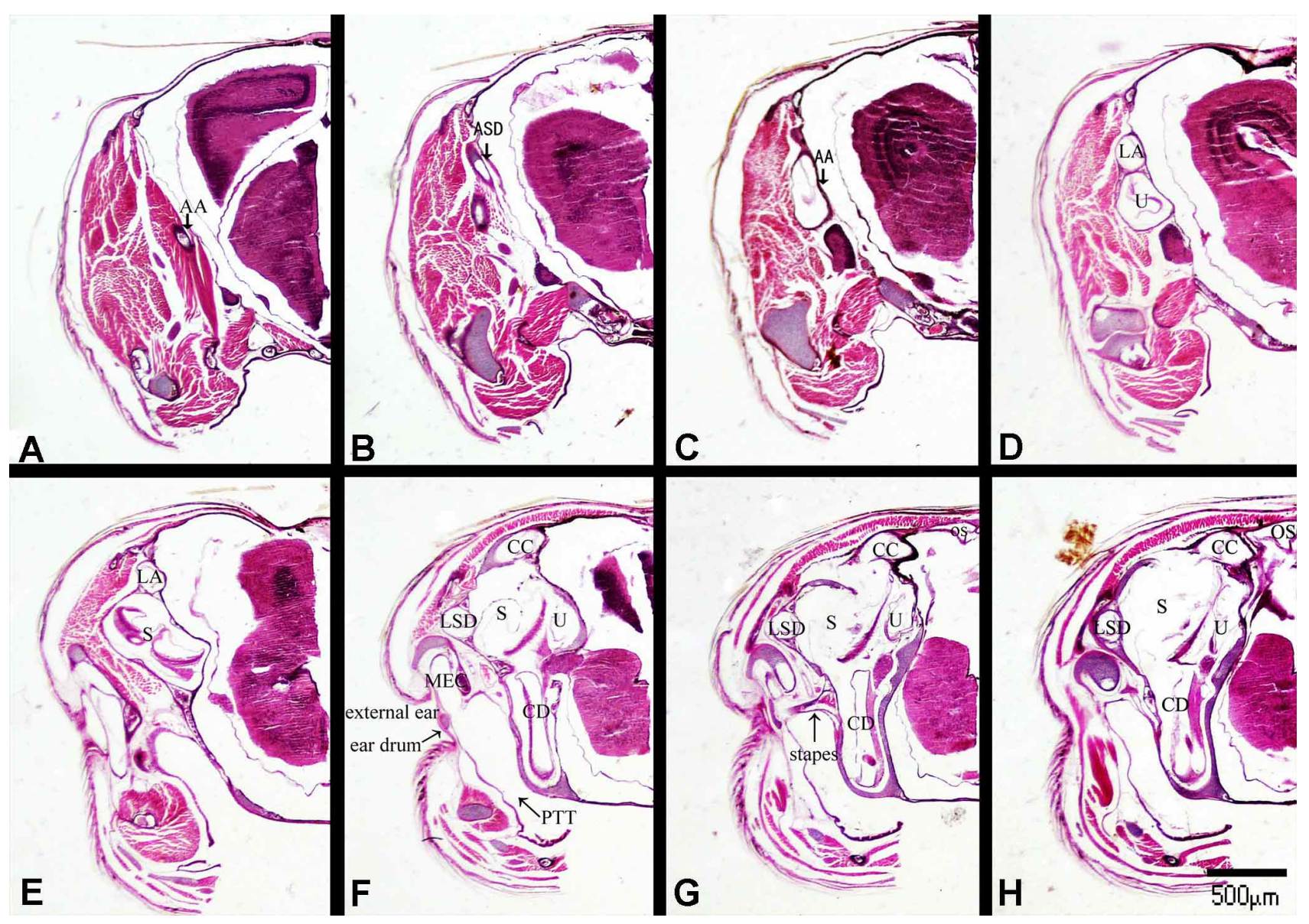

Fig. 1. Histology sections of inner ear in S. tsinlingensis showing the structures from the anterior to posterior. AA, anterior ampulla; ASD, anterior semicircular duct; CC, crus commune; CD, Cochlear duct; LA, lateral ampulla; LSD, lateral semicircular duct; MEC, middle ear cavity; OS, otic saccule; PTT, pharyngotympanic tube; S, saccule; U, Utricle.

se connective tissue, which provided a solid base for the saccule in the vicinity of medial saccular wall. Occupied up to one half of the medial saccular wall, the macula of saccule consisted of closely packed interspersed columnar hair cells. The basal layer of supporting cells expanded their apices toward the edge of macular cavity (Fig. 2-B). According to the anterior and medial part of superior saccular margin, the otic duct was given off and curved between the saccule and utricle inferiorly.

The cochlear duct of $S$. tsinlingensis is not only fairly large and elongate, but also slightly bowed or arched laterally (Fig. 1-F). As an epithelium-lined chamber, the cochlear duct was supported by periotic connective tissue. Sometimes, the highly organized periotic connective tissue was found medial to the saccule upon the same type of density (Figs. 1-G and $\mathrm{H}$ ). In cochlear recess of $S$. tsinlingensis, there was no hint of limbic modifications, limbic lip was absent. In the limbus medial to the papilla, there was a slight elevation accompanied by a moderate thickening of covering epithelium (Fig. 2-D). The basilar papilla, a group of columnar neuroepithelial hair cells, sitted upon the basilar membrane, elongated anteroventrally (Fig .2-E and F). Near the ventral of basilar papilla, it usually increased rapidly to a peak and then quickly subsided. The scala tympani was well-defined (Fig. 2-D).

The elongate, irregular and narrow utricle nearly extended the whole length of vestibule (Figs. 1-F, G and H). At the level of superior sinus foramen, the anterior and posterior semicircular ducts met and became confluent, which jointly emptied into the superior sinus of utricle subsequently. The sacculo-utricular duct was always found (Fig. 2-A). The semicircular duct was enclosed in the bony semicircular canals (Figs. 1-B and G). The ampullae cristae were repositories for neuroepithelial sensory areas (Fig. 2C). Within each ampulla, the planum semilunatum showed an annular ring formed by cells near the cristae (Fig. 2-G ). 

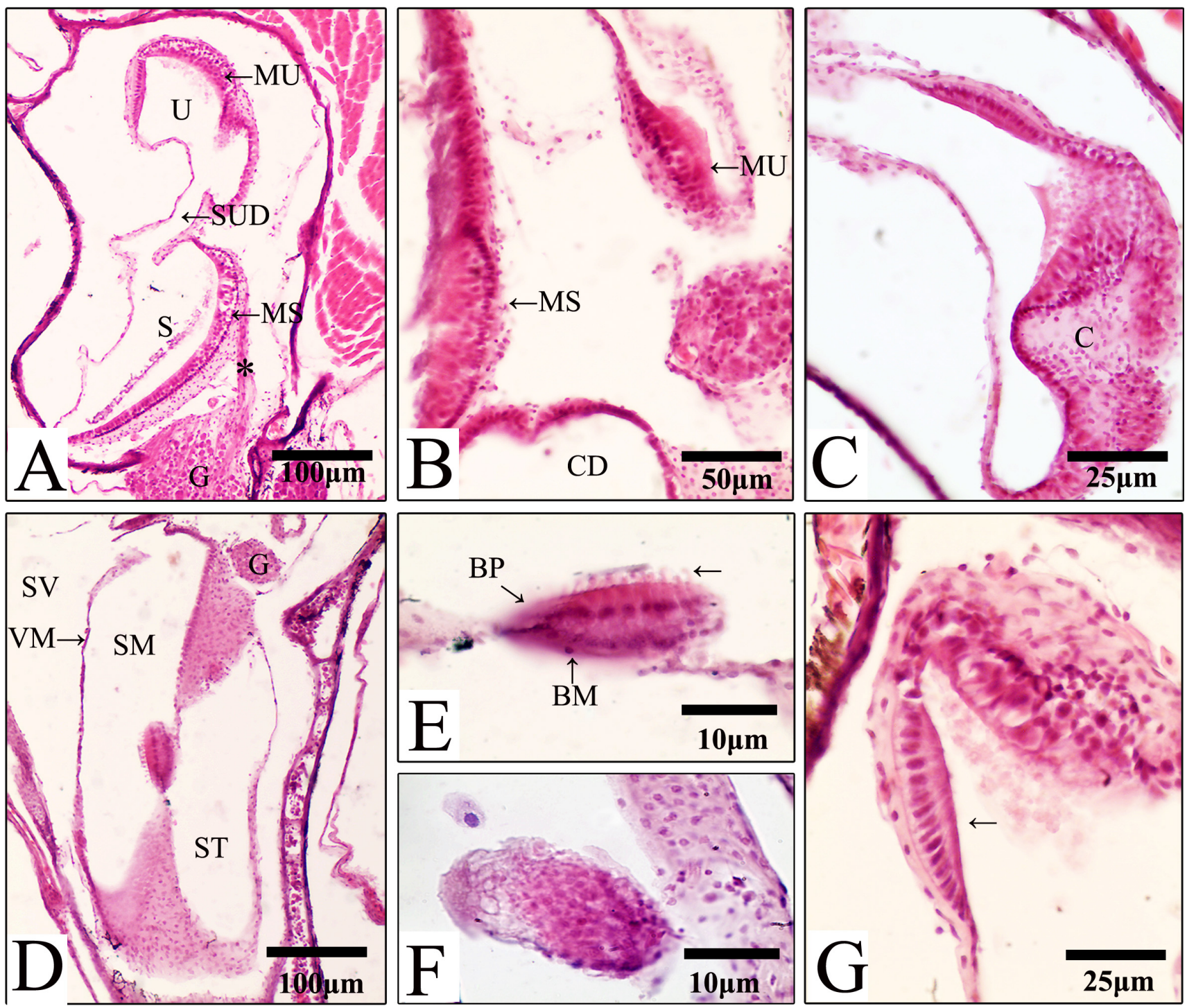

Fig. 2. Histological structure of the membranous labyrinth of inner ear in S. tsinlingensis. (A) Utriculi connected with the saccule by sacculo-utricular duct and a small branch from the ganglion innervated the saccule(*). (B) Macula utriculi and macula sacculi showing packed columnar hair cells interspersed with numerous supportive cells. (C) Crista ampullaris and adjacent epithelium. (D) Transverse section of the cochlear showing scala vestibuli, scala media, scala tympani, and basilar papilla. (E) A basilar papilla showing a rather small sallet on the top surface of ciliary tufts $(\rightarrow)$. (F) The basilar papilla through the region of ventral expansion. (G) Crista ampullaris and adjacent annular ring formed by cells. BP, basilar papilla; BM, basilar membrane; C, cristae; CD, Cochlear duct; G, ganglion; MS, macula sacculi; MU, macula utriculi; S, saccule; SM, scala media; ST, scala tympani; SUD, sacculo-utricular duct; SV, scala vestibuli; U, Utricle; VM, vestibular membrane.

The periotic system. The periotic system comprised the membrana propria of otic labyrinth, internal periosteum of otic capsule, as well as the periotic reticulum (Figs. 1-F, G and $\mathrm{H}$ ). The cisternal septum presented in $S$. tsinlingensis was formulated by the reflection of periotic tissue from the lateral and inferior walls of the saccule to the lateral vestibular wall, which was generally in front of the fenestra ovalis. The wider scala sacculi was found as an expanded periotic channel medial to the medial saccular wall in the vicinity of saccular macula. The scala connected with the lateral periotic channels through a duct coursed between the inferior margin of saccule and superior margin of cochlear duct. Moreover, there was a very short, and superiorlydirected scala in $S$. tsinlingensis. The helicotrema was most common, which crossed over the dorsal side of cochlear duct. The periotic sac bulged by the periotic foramen entered into the recessus scalae tympani and helped form the closing membranes of medial and lateral apertures of recessus. 
GFAPimmunohistochemical localizationin the vestibular organ and the cochlea. At the adult age group, GFAP staining was significantly distributed in the supporting cells of epithelium of utricle, saccule and cochlear duct (Figs. 3-B, D and F). An occasional GFAP positive supporting cells were found in the epithelium of otic sac, lateral semicircular duct, and crus commune (Fig. 3-A, C and E). Strong positive GFAP supporting cells showed dark brown, and lined the basilar membrane at the ventral part and lateral wall of the cochlear duct (Fig. 3-F). GFAP immunoreactivity was high in the supporting cells of utricular and canal ampullae. Furthermore, some GFAP positive non myelinating Schwann cells were observed in other peripheral nervous tissues as well.
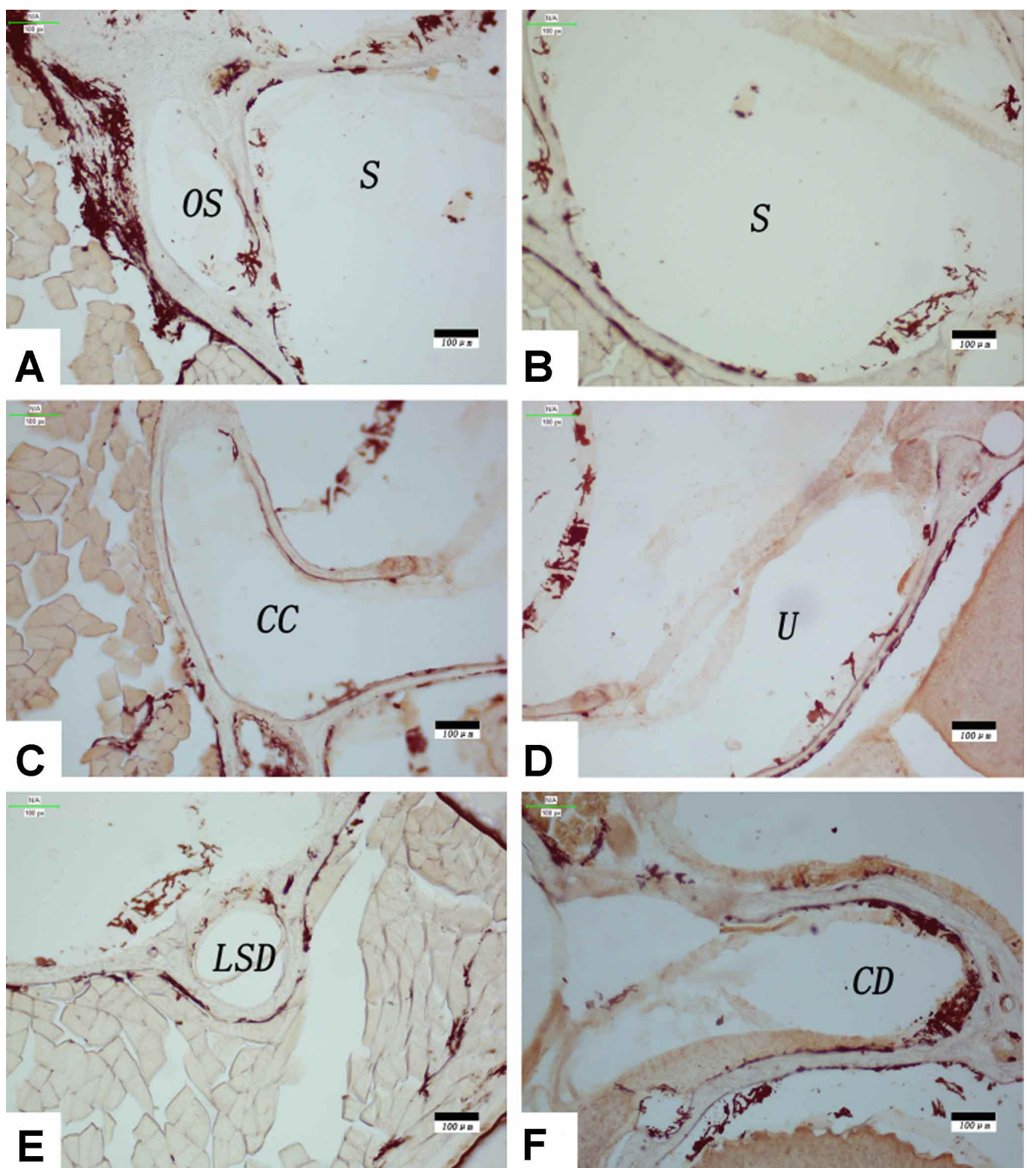

Fig. 3. Immunohistochemical staining of GFAP in the membranous labyrinth of inner ear in adult $S$. tsinlingensis.

At the subadult age group, the pattern of GFAP expression was similar to that in the adult. Strong positive GFAP cells were distributed in the epithelium of utricle, saccule and cochlear duct (Figs. 4-B, D and F). GFAP positive cells were found in the roof wall of otic sac (Fig. 4A) and basilar membrane of semicircular duct sensory areas (Fig. 4-E). GFAP immunostaining was weak in crus commune (Fig. 4-C). cells with GFAP antibody were observed in the epithelium of utricle, saccule and cochlear ducts (Fig. 5-B, D and F). Brown yellow GFAP positive cells were distributed along
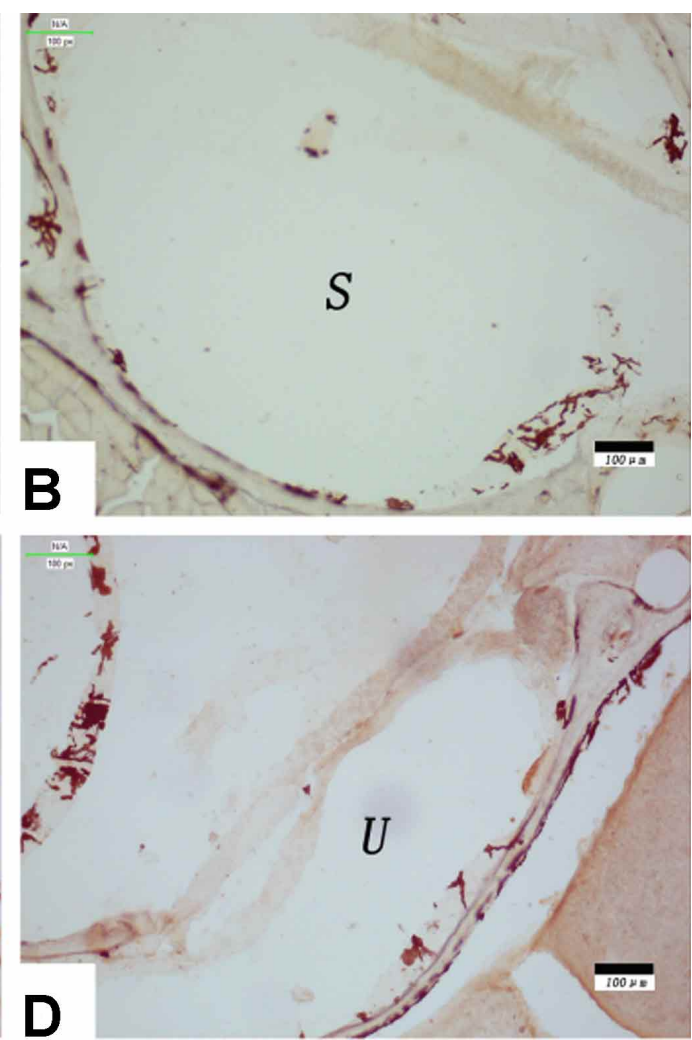

At the juvenile age group, the same immunopositive 

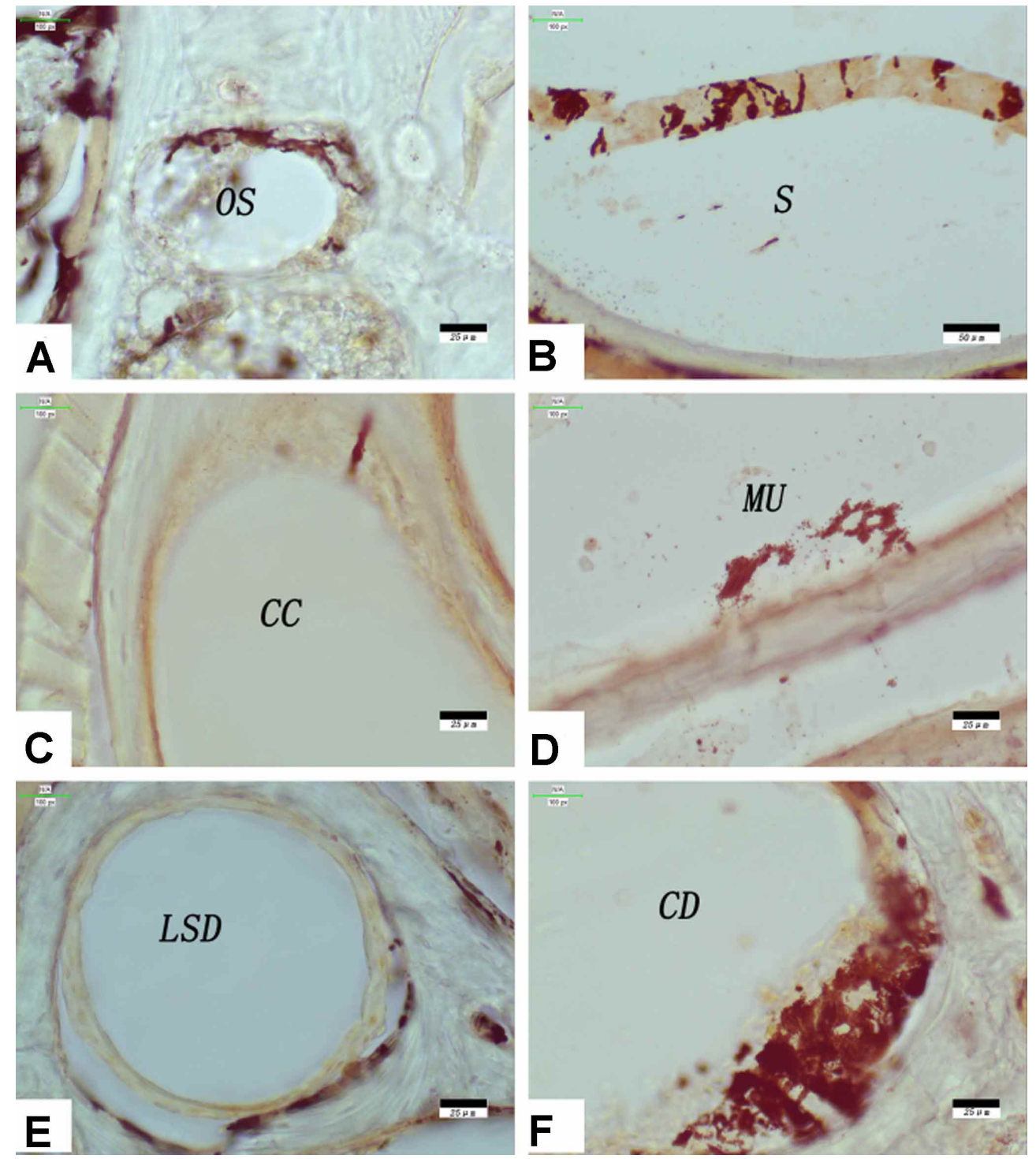

Fig. 4. Immunohistochemical staining of GFAP in the membranous labyrinth of inner ear in subadult $S$. tsinlingensis.

the medial wall of crus commune (Fig. 5-C). However, GFAP positive staining was absent in the epithelium of otic sac (Fig. 5-A). A small number of GFAP immunostaining cells were found in the basilar membrane of lateral semicircular duct (Fig. 5-E).

\section{DISCUSSION}

A clear understanding of anatomy is the prerequisite to understand the hydrodynamic and mechanical stimulation of vertebrate inner ear structures. The two-dimensional views of inner ear in $S$. tsinlingensis is afforded by histological methods. The anatomic structure of inner ear in $S$. tsinlingensis is similar to that of other Scincid lizards (Hamilton, 1964). Therefore, it is assumed that the specific functions of inner ear in S. tsinlingensis are comparable with those of Scincid lizards. Vestibular sensory organs appeared in all vertebrates, which possess relatively similar morphologies, even in widely divergent species. The semicircular canals, physiologically and anatomically homologous in all vertebrates, is a functional part of vestibular system of inner ear that enables $S$. tsinlingensis to coordinate fast and complex movements in threedimensions (Dickson et al.). In contrast, an enormous morphological diversity is existed in reptilian hearing organs (Manley). The cochlear duct of 43 species of skinks, 

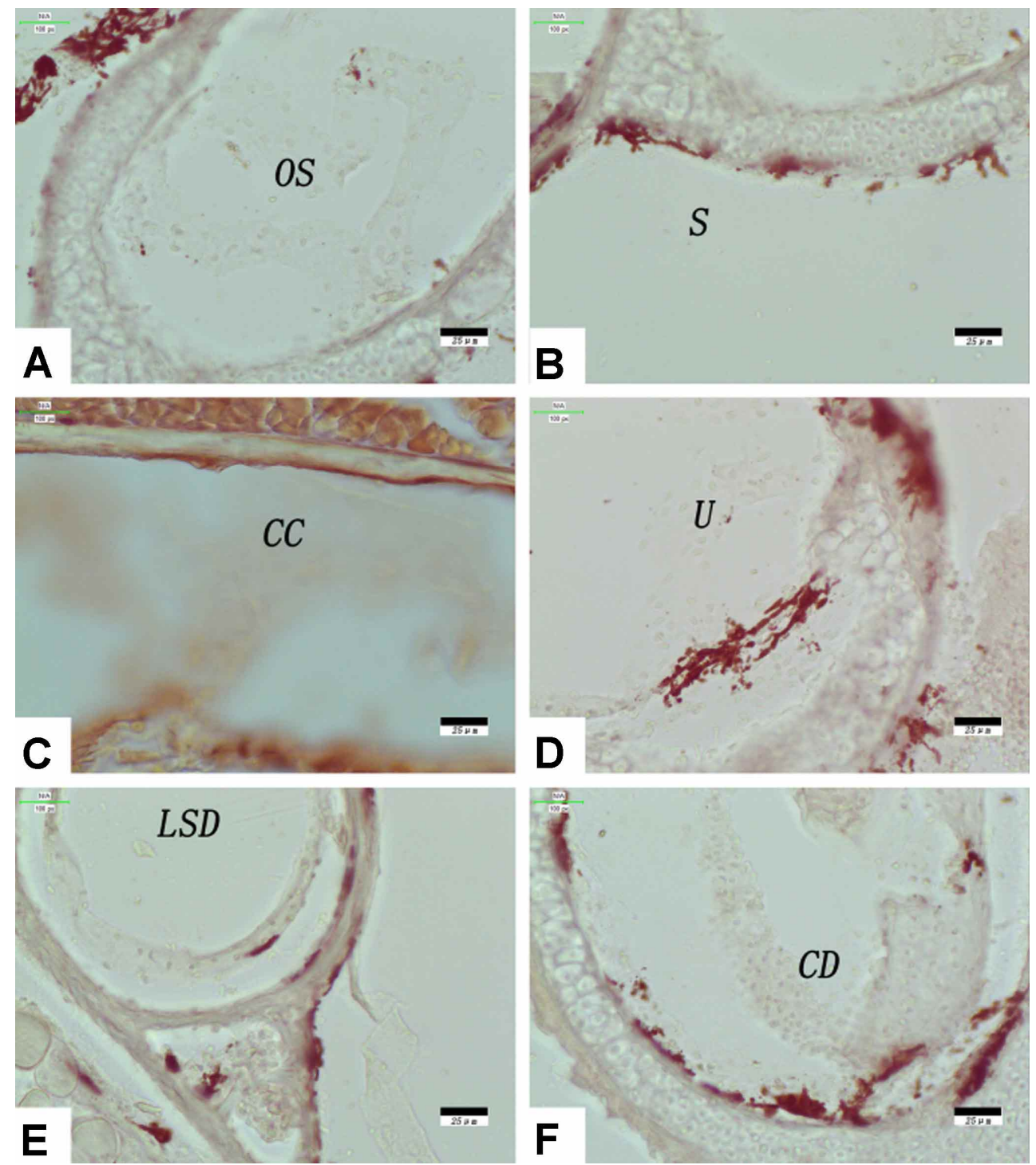

Fig. 5. Immunohistochemical staining of GFAP in the membranous labyrinth of inner ear in juvenile $S$. tsinlingensis.

including S. tsinlingensis, is not only fairly large and elongate, but also slightly bowed or arched laterally (Miller, 1966). In iguanids, skinks and anguids, the tectorial membrane is much narrower than the papilla, which extends over the hair cells only in one region, as it is in $S$. tsinlingensis. The tectorial membrane covers most surface of the medial limbus in Scincidae, but never leaves this surface, so it fails to make any contact with the auditory papilla. Through the operation of inertia principle, the stimulation of hair-cells is achieved through a chain of sallets extending along most of the cochlea, but giving way to the culinen papillae, a single large body in the area of ventral expansion (Wever, 1970).

Despite the great structural variation in lizard basilar papilla, the broad contours of physiologic responses of hearing organs of different lizard families are quite similar. Perhaps this is the lowest common denominator that allows the ear to convey important information concerning dangers in the outside world to the brain (Manley). In gecko species, the papilla basilaris is often stable during the post-natal ontogeny, in terms of overall length, length proportions among the constituent areas, and quantity of hair cells. Among different lizard species, the dependence of auditory sensitivity on animal size was likely supported by inner ear differences, but this relation only derived from the middle ear within one species (Gehr \& Werner). Papilla length or hair cell number in Leiolopisma assatum (Scincidae) didn't increased with the body size (Miller, 1966), which were independent of age in many lizard species (Miller, 1985). 
The membranous inner ear is partly composed of highly specialized epithelia derived from the epithelial lining of otocyst (Kuijpers et al., 1991). A combination of supporting cell division and phenotypic change is included in the underlying mechanisms of sensory regeneration in most nonmammalian inner ears (Warchol, 2011). The loss of a hair cell may cause the partial dedifferentiation of an adjoining supporting cell and allow the cell to divide, produce hair cell progeny or directly re-differentiate as a new hair cell (Brignull et al., 2009). The regeneration evidence of vestibular hair cells with aminoglycoside ototoxicity has been reported only in Podarcis sicula (Avallone et al., 2008). Whether such phenomenon as above exists in S. tsinlingensis deserves further investigation.

GFAP expressing and stem cells-specific astrocytes, located in the subventricular zone in the adult mammalian CNS, could lead to the generation of new neurons (Doetsch et al., 1999). Thus, the supporting cells in sensory epithelia and astrocytic neuronal precursors of CNS may share properties enabling them to become neuronal cells in response to appropriate stimuli (Rio et al.). Immunohistochemical localization of GFAP in the supporting cells of sensory epithelia of cochlea and vestibular organs in S. tsinlingensis was similar to the reports on inner ear of developing and adult mice (Rio et al.). Early after birth, GFAP is expressed in all cochlear supporting cells, with a gradient decreasing in intensity from base to apex. After P15, GFAP expression in the spiral organ (organ of Corti) is mostly limited to supporting cells of inner phalangeal cells, inner margin cells, pillar cells and phalangeal cells (Deiters' cells). At the same time, a small population of limbic cells also showed an expression of gradient from the base to the top. In the vestibular organs, high expression was observed in supporting cells in the extrastriolar areas of utricular macula and canal ampullae, with weaker staining in the saccular macula. In $S$. tsinlingensis, GFAP positive staining from all three different age groups were significantly distributed in the supporting cells of epithelium of utricle, saccule and cochlear duct. These results suggested that GFAP positive supporting cells of inner ear may play roles similar to those of astrocytes or Schwann cells to support the normal development and maintenance of neurons as well as sensory cells (Rio et al.). When the efferent and afferent neurons entering the sensory epithelia in cochlea and vestibular organs, they lose intimate contact with myelinating and nonmyelinating schwannocyti (Schwann cells) and gain intimate contact with various classes of supporting cells (Rio et al.). Thus, it is likely that cytoskeletal protein GFAP may contributes to the normal frequency tuning of cochlea (Rio et al.). In S. tsinlingensis, GFAP labeling was also observed around the vestibular epithelium, and probably corresponding to vestibular transitional cells with similar functional properties as outer sulcus cells.

A new dimension to our knowledge of inner ear cytology was added in our results, which may be helpful in the study of inner ear development. The anatomic structure of inner ear in $S$. tsinlingensis is similar to that of other Scincid lizards, and the inner ear of all three different age groups shows the similar pattern of GFAP expression, which indicates that the distribution of supporting cells are independent of age in $S$. tsinlingensis.

\section{ACKNOWLEDGEMENTS}

This study received financial supports from the Scientific Research Foundation for Doctors of Shanxi Normal University (No. 833174).

YANG, C.; ZHANG, H.; KOU, Z.; ZHANG, Y.; GAO, Z. \&

LIU, B. Histología y localización inmunocitoquímica de la proteína ácida fibrilar glial en el oído interno de Scincella tsinlingensis. Int. J. Morphol., 39(2):497-505, 2021.

RESUMEN: La microestructura del oído interno en Scincella tsinlingensis fue analizada mediante microscopía óptica y por otra parte, fue cuantificada la expresión de la proteína ácida fibrilar glial (GFAP) en el laberinto membranoso, entre los grupos de edad juvenil, subadulto y adulto, utilizándose métodos inmunohistoquímicos. El oído interno de $S$. tsinlingensis se asemejaba al de otros lagartos Scincid tanto en su anatomía como en su histología. El conducto coclear mayor estaba ligeramente arqueado o arqueado lateralmente. No había indicios de modificaciones límbicas y no se evidenció el labio en el receso coclear. La papila basilar alargada anteroventralmente poseía sallets tectoriales especializados. La tinción de GFAP se distribuyó significativamente en las células del epitelio sensorial del conducto coclear, mientras que la mácula utricular y la ampolla del canal mostraron inmunopositividad para el anticuerpo GFAP, con una tinción más débil en la mácula sacular. El oído interno membranoso de los tres grupos de edad diferentes reveló un patrón similar de expresión de GFAP, lo que sugiere que la distribución de las células de soporte son independiente de la edad en $S$. tsinlingensis.

PALABRAS CLAVE: Scincella tsinlingensis; Oído interno; Histología; Células de apoyo.

\section{REFERENCES}

Avallone, B.; Fascio, U.; Balsamo, G. \& Marmo, F. Gentamicin ototoxicity in the saccule of the lizard Podarcis Sicula induces hair cell recovery and regeneration. Hear. Res., 235(1-2):15-22, 2008. 
Brignull, H. R.; Raible, D. W. \& Stone, J. S. Feathers and fins: nonmammalian models for hair cell regeneration. Brain Res., 1277:12-23, 2009.

Dickson, B. V.; Sherratt, E.; Losos, J. B. \& Pierce, S. E. Semicircular canals in Anolis lizards: ecomorphological convergence and ecomorph affinities of fossil species. R. Soc. Open Sci., 4(10):170058, 2017.

Gao, Y,; Li, L.; Zhao, Y., Zhu, N. \& Yang, C. Age-dependent microstructure and immunohistochemical localization of glial fibrillary acidic protein in the retina of Scincella tsinlingensis. Sichuan J. Zool., 37(4):439-44, 2018.

Gehr, D. D. \& Werner, Y. L. Age effects and size effects in the ears of gekkonomorph lizards: inner ear. Hear. Res., 200(1-2):38-50, 2005.

Hamilton, D. W. The innerear of lizards. I. Gross structure. $J$. Morphol., 115:255-71, 1964.

Horner, K. C.; Troadec, J. D.; Dallaporta, M. \& Pio, J. Effect of chronic estradiol administration on vimentin and GFAP immunohistochemistry within the inner ear. Neurobiol. Dis., 35(2):201-8, 2009.

Kuijpers, W.; Tonnaer, E. L.; Peters, T. A. \& Ramaekers, F. C. Expression of intermediate filament proteins in the mature inner ear of the rat and guinea pig. Hear. Res., 52(1):133-46, 1991.

Manley, G. A. \& Köppl, C. What have lizard ears taught us about auditory physiology? Hear. Res., 238(1-2):3-11, 2008.

Manley, G. A. Evolution of structure and function of the hearing organ of lizards. J. Neurobiol., 53(2):202-11, 2002.

Miller, M. R. Quantitative studies of auditory hair cells and nerves in lizards. J. Comp. Neurol., 232(1):1-24, 1985.

Miller, M. R. The cochlear duct of lizards and snakes. Am. Zool., 6(3):4219, 1966.

Neang, T.; Chan, S. \& Poyarkov Jr., N. A. A new species of smooth skink (Squamata: Scincidae: Scincella) from Cambodia. Zool. Res., 39(3):22040, 2018.

Pfaff, C.; Schultz, J. A. \& Schellhorn, R. The vertebrate middle and inner ear: A short overview. J. Morphol., 280(8):1098-105, 2019.

Rinkwitz, S.; Bober, E. \& Baker, R. Development of the vertebrate inner ear. Ann. N. Y. Acad. Sci., 942:1-14, 2001.

Rio, C.; Dikkes, P.; Liberman, M. C. \& Corfas, G. Glial fibrillary acidic protein expression and promoter activity in the inner ear of developing and adult mice. J. Comp. Neurol., 442(2):156-62, 2002.

Warchol, M. E. Sensory regeneration in the vertebrate inner ear: Differences at the levels of cells and species. Hear. Res., 273(1-2):72-9, 2011.

Wever, E. G. The lizard ear: Gekkonidae. J. Morphol., 143(2):121-65, 1974.

Wever, E. G. The lizard ear: Scincidae. J. Morphol., 132(3):277-92, 1970.

Yang, C. \& Wang, L. Histological and morphological observations on tongue of Scincella tsinlingensis (Reptilia, Squamata, Scincidae). Micron, 80:24-33, 2016

Yang, C.; Kou, Z.; Li, L.; Gao, Y. \& Gong, Z. Histomorphology of vomeronasal organ in Scincella tsinlingensis. Int. J. Morphol., 38(3):602-10, 2020a.

Yang, C.; Li, L.; Kou, Z.; Zhang, H.; Wang, L.; Zhao, Y. \& Zhu, N. Telencephalon Cytoarchitecture of tsinling dwarf skinks (Scincella tsinlingensis). Micron, 130:102799, 2020b.

Yang, C.; Wang, L.; Xing, X.; Gao, Y. \& Guo L. Seasonal variation in telencephalon cell proliferation in adult female tsinling dwarf skinks (Scincella tsinlingensis). Brain Res., 1662:7-15, 2017.

Zhao, Y.; Li, L. \& Kou, Z. T. Effect of a-asarone on cell proliferation during the stage of blastema formation in tail regeneration of Scincella tsinlingensis. Chin. J. Wildl., 41(1):165-70, 2020.

\author{
Corresponding author: \\ Chun Yang \\ School of Life Sciences \\ Shanxi Normal University \\ Linfen, Shanxi Province \\ CHINA
}

Email:yangchun774@163.com

Received: 02-09-2020

Accepted: $26-11-2020$ 